\section{Leptospirosis complicated by fatal intracerebral haemorrhage}

Leptospirosis is a potentially fatal bacterial disease that has traditionally been associated with occupations such as mining and farming, in which the risk of contact with contaminated rodent urine is fairly high. ${ }^{1}$ We describe a patient who contracted leptospirosis while on a walking holiday in the inner Hebrides. Despite early diagnosis and apparently successful initial treatment he died after a spontaneous intracerebral haemorrhage.

\section{Case report}

A 39 year old man was transferred to Glasgow from Islay, an island in the inner Hebrides. He had collapsed while walking in the hills two days previously and had been admitted to the local hospital confused, dehydrated, and shocked. He was rehydrated and, on arrival in Glasgow, seemed well.

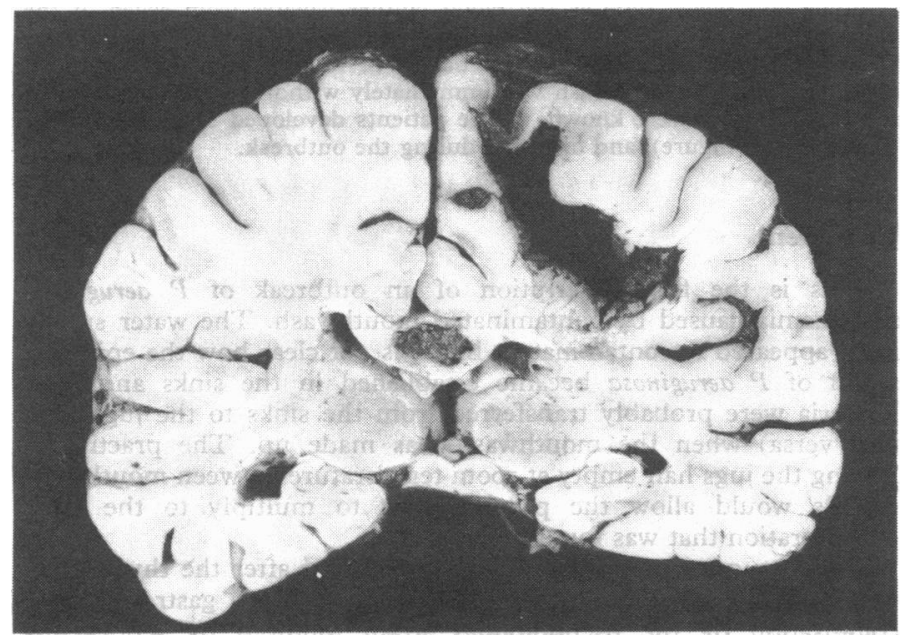

Coronal section of brain at level of the pulvinar of the thalamus, with unconnected haematomas in the midline of the corpus callosum and the white matter of the right parietal lobe.

He began to vomit overnight and became jaundiced. Deepening jaundice was accompanied by diarrhoea, profuse vomiting, hiccups, calf muscle pains, iridocyclitis, and subconjunctival haemorrhages.

Haemoglobin concentration, differential white cell count, erythrocyte sedimentation rate, coagulation screen, and fibrin degradation products were all normal. The platelet count was reduced to $69 \times 10^{9} / 1$ but rose to $200 \times 10^{9} / 1$ one week after admission. Routine biochemical tests on the day after admission gave the following: urea $36 \mathrm{mmol} / 1(216 \mathrm{mg} / 100 \mathrm{ml})$, creatinine $643 \mu \mathrm{mol} / 1(7.3 \mathrm{mg} / 100 \mathrm{ml})$, bilirubin $196 \mu \mathrm{mol} / 1(11.5 \mathrm{mg} / 100 \mathrm{ml})$, alkaline phosphatase $108 \mathrm{U} / \mathrm{l}$, serum aspartate aminotransferase $1884 \mathrm{U} / \mathrm{l}$, serum alanine aminotransferase $2796 \mathrm{U} / \mathrm{l}$, and creatine kinase $9257 \mathrm{U} / \mathrm{l}$. Results of serological tests for hepatitis A and B and routine viral and brucella titres proved negative. Early the next day fresh specimens of blood and urine were examined under dark ground microscopy. No organisms were seen in the urine, but leptospires were identified in the blood sample by their characteristic morphology and "paddle wheel" motility. Two guinea pigs were inoculated intraperitoneally with this infected blood.

After diagnosis treatment with intravenous benzylpenicillin ( 2 megaunits four times daily) was started. His clinical state steadily improved, and by the 12th day serum creatinine concentration had fallen to $169 \mu \mathrm{mol} / 1$ $(1.9 \mathrm{mg} / 100 \mathrm{ml})$, bilirubin concentration to $61 \mu \mathrm{mol} / 1(3.6 \mathrm{mg} / 100 \mathrm{ml})$, and serum aspartate aminotransferase activity to $108 \mathrm{U} / \mathrm{l}$. That evening he developed slurring of speech and left sided weakness; within 30 minutes he was in coma, with a fixed dilated right pupil. Computed tomography showed a right frontal haematoma, with massive shift of midline structures to the left. The platelet count was $69 \times 10^{9} / 1$, and a coagulation screen was normal. Despite prompt evacuation of the haematoma he died 19 days postoperatively. At necropsy the brain weighed $1320 \mathrm{~g}$ and showed evidence of raised intracranial pressure. In addition to the evacuated haematoma several satellite haematomas measuring a few millimetres in diameter were present, one of which was in the splenium of the corpus callosum (figure). Histological examination of the cerebral vessels did not show any evidence of vasculitis.

The two guinea pigs died three weeks after inoculation with infected blood. At necropsy both animals showed pathological changes of leptospirosis and the presence of leptospires was confirmed by Dieterle's method in spleen, liver, and kidneys. No serotype was obtained because of autolysis. Leptospira titres in serial samples of the patient's serum later proved to be negative.

\section{Comment}

The clinical picture in this case was that of Leptospira icterohaemorrhagiae, ${ }^{2}$ although confirmation of the serotype was not obtained. Serological tests may give negative results even in proved infection, as here. ${ }^{3}$ Intracerebral haemorrhage complicating leptospirosis has been reported in two cases. ${ }^{4}$ Our patient had multiple areas of intracerebral haemorrhage despite normal coagulation and a platelet count that never fell below $69 \times 10^{9} / 1$. He was not hypertensive and did not have evidence of a vascular anomaly or mycotic aneurysm. Cerebral vasculitis or direct spirochaete invasion of the vessel walls may have been responsible for these lesions.

Rapid diagnosis of leptospirosis on clinical and laboratory criteria is essential for early inception of specific antibacterial treatment. Nevertheless, intracerebral haemorrhage is a rare but important complication that may occur in the recovery phase despite normal coagulation state and platelet count.

We thank Professor D I Graham of the department of neuropathology, Institute of Neurological Sciences, Glasgow, for his advice and help.

1 Leptospirosis Reference Laboratory and Communicable Disease Surveillance Centre (Public Health Laboratory Service). Leptospirosis in man, British ed F 1983;287:1365-6.

2 Sitprija V. Infections: leptospirosis. In: Weatherall DJ, Ledingham JGG, Oxford textbook of medicine. Oxford: Oxford University Press, 983:297-300.

3 Adler B, Faine S. The antibodies involved in the human immune response to leptospiral infection. 7 Med Microbiol 1978;2:387-400.

4 Lessa I, Cortes E. Cerebrovascular accident as a complication of leptospirosis. Lancet 1981 ;ii:1113.

(Accepted 26 September 1984)

Western Infirmary, Glasgow G11 6NT

MARGARET A FORWELL, MRCP, medical registrar

PENELOPE J REDDING, MRCPATH, senior registrar in bacteriology

MARTIN J BRODIE, MD, MRCP, consultant clinical pharmacologist

Institute of Neurological Sciences, Southern General Hospital, Glasgow

DOUGLAS DE R GENTLEMAN, BSC, FRCS, registrar in neurosurgery

Correspondence to: $\operatorname{Dr} \mathrm{M}$ J Brodie.

\section{Non-accidental injury in children: two cases of concealment of self injury}

People who work with children have to be aware of many explanations for children's injuries. Roberton et al showed that up to $60 \%$ of children aged 3 may show signs of recent injury. ${ }^{1}$ Meadow described children who are continually subjected to medical investigation because of artefacts caused by their parents. ${ }^{2}$ Non-accidental injury inflicted by others is well documented, ${ }^{3}$ but we present two cases of concealed self injury, in which the blame for injury was attributed to others.

\section{Case reports}

Case 1-A 6 year old girl lived with foster parents, having been taken into care when aged 3 because of her mother's chronic mental illness. One of us (RB) saw her, her foster parents, and a social worker because on several occasions she had been found at school to have bruises on her legs. The head teacher had reported the bruising to the school medical officer and the foster parents, who were outraged at the suggestion that they had injured her. She was not forthcoming, but would talk about life at school and home At a subsequent interview she showed how she bruised herself by hitting the inner aspects of both thighs and calves with her fist. Discussion with the foster parents showed that they had difficulties in verbalising their anger. They had suspected that the girl might be injuring herself but could not be sure and had not known what to do. As they could not build a trusting relationship sufficiently quickly they thought that she should be removed from their care because of the accusations made by school staff and other authorities. She had to return to institutional life. 
Case 2-A girl aged 9 was taken into care on a place of safety order after her mother was thought to have burnt her deliberately on the buttocks with an electric iron. The mother was pregnant and had two other younger children. The girl had repeatedly played her mother up in the past after a long, early separation from her, and the family was well known to social workers. She showed her injury to her teacher, who contacted the police, and she was placed in an observation and assessment centre where one of us (PG) was teacher in charge. The mother was remanded in custody and the younger children were placed in children's homes. The girl gradually formed a trusting relationship in the classroom with her teachers and admitted that she had injured herself after being punished harshly. With her permission the teachers discussed this with her social worker. This was timely because the mother was about to be tried for grievous bodily harm; had she been convicted she would almost certainly have been sent to prison, so that the other children would have had to be taken into care. The girl remained in care with access to her family and was educated in a school for maladjusted children.

\section{Comment}

Many children who are rejected and ill treated start to feel worthless and try to punish themselves. ${ }^{45}$ Psychodynamics explains this offence against self and society as a guilt reaction. Distinguishing between non-accidental injury that is self inflicted and that inflicted by others is not easy. In these cases hours of skilled conversation with the children were necessary to allow them to admit their secrets.

We have drawn attention to the concealment of self inflicted injury to show that parental abuse and overt self mutilation are not the only explanations of non-accidental injury. Although it is not common, this type of injury should be borne in mind in making the differential diagnosis to prevent possible miscarriages of justice.

We are grateful to the Headley Library (National Society for the Prevention of Cruelty to Children) for its generous help.

1 Roberton D, Barbor P, Hull D. Unusual injury: recent injury in normal children and children with suspected non-accidental injury. Br Med f 1982;285:1399. Meadow R. Factitious illness: the hinterland of child abuse. In: Recent advances in paediatrics. No. 7. Edinburgh: Churchill Livingstone, 1984 Oxtoby $M$, ed. Taking a stand: child psychiatrists in custody, access and disputed Green A. Self-destructive behavior in battered children. Am F Psychiatry 1978; de Young M. Self injurious behaviour in incest victims: a research note. Child Welfare 1982;61:577-84.

(Accepted 2 October 1984)

Ealing Child Guidance Clinic, Ealing

ROBIN BENIANS, MD, FRCPSYCH, consultant psychiatrist

London SW12 8EA

PATRICIA GOLDACRE, BA, educational therapist and teacher

Correspondence to: Dr R Benians, 3 Brodrick Road, London, SW 17 7DZ.

\section{Outbreak of septicaemia due to contaminated mouthwash}

Patients may become colonised with Pseudomonas aeruginosa in hospital, and medicaments used in wards are possible sources. ${ }^{1}$ In immunocompromised patients colonisation is often associated with the development of septicaemia. ${ }^{2}$ We report an outbreak of septicaemia due to $P$ aeruginosa that occurred in an oncology ward and was caused by contaminated thymol mouthwash.

\section{Patients, methods, and results}

The outbreak affected eight out of 15 patients with leukaemia or lymphoma resident in a male oncology ward in the first six weeks of 1984. All eight patients had received cytotoxic chemotherapy before or during this outbreak.

Investigations began when we noticed a cluster of four cases (cases 2-5, figure). We concentrated on three possible sources common to all the patients with septicaemia-namely, indwelling Hickman catheters and two types of antiseptic mouthwash. On this ward hexetidine (Oraldene) mouthwash was given to patients complaining of sore mouths and thymol mouthwash was distributed to all patients after each meal. Cultures from the Hickman lines and hexetidine mouthwash were sterile, but, residual mouthwash in the two jugs used to distribute the thymol was macroscopically turbid and was shown to contain $P$ aeruginos $a$ at a concentration of $1.0 \times 10^{5}$ organisms $/ \mathrm{ml}$ after culture. These jugs were also used to make up the thymol mouthwash from tablets with tap water from two sinks in the ward. The jugs often remained half full for several hours between meals at room temperature. $P$ aeruginosa was also cultured from swabs taken from both sinks and their taps in the ward. Similar swabs were taken from the female oncology ward, where thymol was made up individually for each patient, but no pseudomonas was grown. To investigate whether the water supply was contaminated samples of water from the tanks supplying the sinks in the male ward were cultured, but no $P$ aeruginosa was grown. Cultures of the thymol tablets in use were sterile.

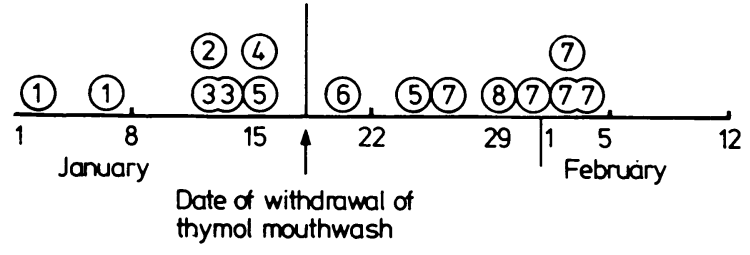

Patients in whom Pseudomonas aeruginosa was isolated from blood cultures during outbreak (case numbers shown within circles).

All strains of $P$ aeruginosa isolated from the jugs and sinks had the same serotype and phage type as the blood culture isolates from seven of the patients with septicaemia. The patient with a different strain of $P$ aeruginosa was nursed in a side room and was not given thymol from the communal jugs. The thymol mouthwash was immediately withdrawn when the initial results of culture were known. Three patients developed septicaemia after this, however (figure), and one died during the outbreak.

\section{Comment}

This is the first description of an outbreak of $P$ aeruginosa septicaemia caused by contaminated mouthwash. The water supply itself appeared uncontaminated, but it is not clear how the epidemic strain of $P$ aeruginosa became established in the sinks and jugs. Bacteria were probably transferred from the sinks to the jugs (and vice versa) when the mouthwash was made up. The practice of leaving the jugs half empty at room temperature between mouthwash rounds would allow the pseudomonas to multiply to the large concentration that was found.

The new cases of septicaemia that occurred after the thymol was withdrawn might be explained by preceding gastrointestinal colonisation by the pseudomonas strain followed by septicaemia (data to be published). Widespread use of antibiotics probably reduced the resistance of these patients to colonisation. ${ }^{3}$ Once colonised, immunocompromised patients commonly develop septicaemia with $P$ aeruginosa, probably as a result of diminished defences against invasion after cytotoxic chemotherapy. ${ }^{2}$

The low mortality in this outbreak is in contrast to that reported at other centres ${ }^{45}$ and may partly have been due to the prompt use of antipseudomonal chemotherapy. Communal medications are an unneccessary hazard, particularly in oncology wards.

We thank Dr T A Lister for allowing us to present details of patients under his care, and Dr T L Pitt, division of hospital infection, Central Public Laboratory, Colindale, for typing the strains in this study. We also thank Miss S O'Farrell for technical help and Miss L Hall for secretarial help. MAR was funded by the Imperial Cancer Research Fund.

1 Shooter RA, Cooke EM, Gaya $\mathrm{H}$, et al. Food and medicaments as possible sources of hospital strains of Pseudomonas aeruginosa. Lancet $1969 ; \mathrm{i}: 1227-9$.

Newman KA, Schimpff SC, Young VM, Wiernik PH. Lessons learned from surveillance cultures in patients with acute non-lymphocytic leukemia. Usefulness for epidemiologic, preventative and therapeutic research. Am $\mathcal{f} \mathrm{Med}$ $1981 ; 70: 423-31$

3 Van der Waaij D, Berghuis JM, Lekkerkerk JEC. Colonisation resistance of the digestive tract of mice during systemic antibiotic treatment. Fournal of Hygiene (Cambridge) $1972 ; 70: 605-10$.

4 Singer C, Kaplan $\mathrm{MH}$, Armstrong D. Bacteremia and fungemia complicating neoplastic disease. A study of 364 cases. Am J Med 1977;62:731-42.

5 Cross A, Allen JR, Burke J, et al. Nosocomial infections due to Pseudomonas aeruginosa: review of recent trends. Rev Infect Dis 1983;5:S837-45.

(Accepted 26 September 1984)

Departments of Medical Microbiology and Medical Oncology, St Bartholomew's Hospital, London EC1A 7BE

I R STEPHENSON, MA, MB, lecturer in microbiology

$S$ R HEARD, MB, PHD, research registrar in microbiology

$M$ A RICHARDS, MB, MRCP, clinical research fellow in oncology

$S$ TABAQCHALI, MB, MRCPATH, reader and honorary consultant in microbiology

Correspondence to: Dr S Tabaqchali. 